\title{
CORREÇÃO DA ACIDEZ DO SOLO EM FUNÇÃO DE MODOS DE INCORPORAÇÃO DE CALCÁRIO
}

\author{
CORRECTION OF SOIL ACIDITY IN FUNCTION \\ OF LIME INCORPORATION MANNERS
}

\section{Pedro Henrique Weirich Neto ${ }^{1}$ Eduardo Fávero Caires ${ }^{2}$ Altair Justino $^{3}$ Jeferson Dias $^{4}$}

\section{RESUMO}

A solubilização do calcário no solo, sem o que não ocorre neutralização da acidez, demanda tempo e exige incorpo ração para aumentar o contato entre o corretivo e os colóides do solo. Com o objetivo de avaliar a correção da acidez do solo em função de diferentes modos de incorporação de calcário, foi conduzido um experimento, no ano agrícola 1993/94, em um Latossolo vermelho-escuro, distrófico, de campo nativo, do município de Ponta Grossa (PR). O delineamento experimental empregado foi o de blocos ao acaso, em parcelas subdivididas, com três repetiçoes. Os tratamentos foram constituídos por cinco modos de incorporação: arado de discos mais duas gradagens, grade aradora mais duas gradagens, enxada rotativa, arado escarificador mais duas gradagens $e$ distribuição na superfície sem incorporação, e por quatro doses de calcário dolomítico: 0 ,

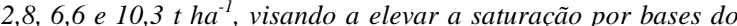
solo a 30, 60 e 90\%. A planta teste utilizada foi o milho. Verificou-se que o modo de incorporação do corretivo no solo afeta a sua eficiência em relação à profundidade no perfil, na qual há neutralização da acidez. Houve elevação da saturação por bases do solo até a camada de $20 \mathrm{~cm}, 15 \mathrm{~cm}$ e $10 \mathrm{~cm}$, respectivamente, para os seguintes modos de incorporação: enxada rotativa, arado de discos ou grade aradora e arado escarificador ou calcário distribuído na superfície sem incorporação. Os valores de saturação por bases desejados não foram alcançados, três meses após a calagem, independente do modo de incorporação de calcário.

Palavras-chave: acidez do solo, calagem, modos de incorporação.

\section{SUMMARY}

The solubilization of lime in soil, without which the acidity neutralization does not occur, demands time and requires incorporation for increasing the contact between lime and soil coloides. In order to study the correction of soil acidity in function of lime incorporation manners, a field experiment was carried out, in Ponta Grossa, State of Paraná, Brazil, in a dystrophic Dark Red Latosol, in native field. A randomized complete block design was used, with three replications, in a split-plot experiment. The treatments consisted of five incorporation methods: disk plowing plus two spring disk harrowing, off-set harrowing plus two spring disk harrowing, rotary tilling, chisel plowing plus two spring disk harrowing and lime distribution on the surface without incorporation (main plots), and four rates of dolomitic limestone: 0, 2.8, 6.6 and $10.3 \mathrm{tha}^{-1}$, in order to raise base saturation of soil to 30, 60 and $90 \%$ (subplots). The cultivated plant was maize. The results showed that the lime incorporation manner in the soil affects its efficiency in relation to the depth in the profile in which there is neutralization of the acidity. There was elevation in base saturation of the soil to the layer of $20 \mathrm{~cm}, 15 \mathrm{~cm}$ and $10 \mathrm{~cm}$, respectively, for the following incorporation manners: rotary tilling, disk plowing or off-set harrowing and chisel plowing or lime distribution on the surface without incorporation. The saturation values for wanted bases were not reached, three months after liming, independent in the incorporation manner of lime.

Key words: soil acidity, liming, manners of incorporation.

\section{INTRODUÇÃO}

A maioria dos trabalhos têm demonstrado a necessidade de calagem para obtenção de altas produtividades em solos ácidos brasileiros. Esses solos, em geral, apresentam toxicidade de alumínio e de manganês, associada às deficiências de cálcio,

\footnotetext{
${ }^{1}$ Engenheiro Agrícola, Professor Auxiliar, Departamento de Ciência do Solo e Engenharia Agrícola, Universidade Estadual de Ponta Grossa

${ }^{2}$ Engenheiro Agrônomo, Doutor, Professor Adjunto, Departamento de Ciência do Solo e Engenharia Agrícola, Universidade Estadual de Ponta Grossa, Bolsista do CNPq. CP 992/3, 84010-330 - Ponta Grossa, PR. E-mail: efcaires@uepg.br. Autor para correspondência.

${ }^{3}$ Engenheiro Agrônomo, Doutor, Professor Adjunto, Departamento de Ciência do Solo e Engenharia Agrícola, Universidade Estadual de Ponta Grossa.

${ }^{4}$ Engenheiro Agrônomo formado pela Universidade Estadual de Ponta Grossa.
} 
magnésio e fósforo (JACKSON, 1967). As baixas produções observadas nos solos ácidos podem ser consequiência do menor enraizamento das plantas, prejudicando a absorção de água e nutrientes (OLMOS \& CAMARGO, 1976; RITCHEY $\boldsymbol{e t}$ al.,1980).

Os materiais corretivos da acidez do solo mais usados na agricultura são rochas calcárias moídas, constituídas por misturas de minerais como a calcita e a dolomita, os quais possuem em sua composição carbonatos de cálcio e/ou magnésio, que são pouco solúveis em água. Para que a acidez do solo seja neutralizada, as partículas de solo devem entrar em contato com o calcário ou com os produtos de sua transformação. Decorre daí a necessidade de incorporar o calcário no solo da melhor forma possível, o que nem sempre se consegue fazer em condições de campo.

De acordo com a recomendação de calagem (MUZILLI et al., 1978; RAIJ et al., 1985), a incorporação do calcário no solo deve ser feita mediante aplicação de metade da dose antes da aração e outra metade após, com posterior gradagem. Entretanto, são raros os trabalhos publicados que utilizam essa recomendação.

Apesar do método de determinação da necessidade de calagem baseado na elevação da saturação por bases do solo apresentar fundamento científico adequado, têm sido freqüentemente relatados na literatura resultados onde os valores de saturação por bases determinados após a calagem foram inferiores aos estimados pelo método (QUAGGIO et al. 1982a,b; CAIRES \& ROSOLEM, 1993; OLIVEIRA et al., 1997). Esse comportamento pode estar relacionado a diversas causas, entre as quais o modo de incorporação do corretivo no solo, cuja influência pode ser marcante.

Este trabalho foi desenvolvido com o objetivo de avaliar a correção da acidez do solo, três meses após a calagem, em função de diferentes modos de incorporação de calcário e verificar a influência destes sobre a eficiência do método de determinação da necessidade de calagem baseado na elevação da saturação por bases do solo.

\section{MATERIAL E MÉTODOS}

O experimento foi instalado na Fazenda Escola Capão da Onça, da Universidade Estadual de Ponta Grossa-PR, em um Latossolo vermelho-escuro distrófico, de campo nativo. Análises químicas (PAVAN et al., 1991) e granulométricas (EMBRAPA, 1997) de solo, da camada de 0-20cm, realizadas antes da instalação do experimento, revelaram os seguintes resultados: $\mathrm{pH} \quad\left(\mathrm{CaCl}_{2}, 0,01 \mathrm{~mol}\right.$ $\left.\mathrm{L}^{-1}\right) 3,9 ; 97,5 \mathrm{mmol}_{\mathrm{c}} \mathrm{dm}^{-3} \mathrm{de} \mathrm{H}^{+}+\mathrm{Al}^{3+} ; 17 \mathrm{mmol}_{\mathrm{c}} \mathrm{dm}^{-3}$ de $\mathrm{Al}^{3+}, 4 \mathrm{mmol}_{\mathrm{c}} \mathrm{dm}^{-3}$ de $\mathrm{Ca}^{2+} ; 3 \mathrm{mmol}_{\mathrm{c}} \mathrm{dm}^{-3}$ de $\mathrm{Mg}^{2+} ; 0,8 \mathrm{mmol}_{\mathrm{c}} \mathrm{dm}^{-3}$ de $\mathrm{K}^{+} ; 1,1 \mathrm{mg} \mathrm{dm} \mathrm{dm}^{-3}$ de $\mathrm{P}$ (Mehlich-1); 27. dm de matéria orgânica e $7 \%$ de saturação por bases e teores de argila, silte e areia, respectivamente, de 220,210 e $570 \mathrm{~g} \mathrm{~kg}^{-1}$.

Os tratamentos foram constituídos por cinco modos de incorporação de calcário: (M1) distribuição de metade da dose na superfície, passagem de arado de discos, distribuição da outra metade da dose, mais duas gradagens com grade niveladora; (M2) metade da dose na superfície, passagem de grade aradora, distribuição de outra metade da dose, mais duas gradagens com grade niveladora; (M3) distribuição do corretivo na superfície e incorporação com enxada rotativa; (M4) metade da dose na superfície, passagem de arado escarificador, distribuição de outra metade da dose, mais duas gradagens com grade niveladora; (M5) distribuição do corretivo na superfície sem incorporação e por quatro doses de calcário dolomítico: 0; 2,8; 6,6 e 10,3 t $\mathrm{ha}^{-1}$, com $84 \%$ de PRNT, visando a elevar a saturação de bases do solo a 30, 60 e 90\%. O calcário foi aplicado com três meses de antecedência da semeadura. $\mathrm{O}$ delineamento experimental empregado foi o de blocos ao acaso em parcelas subdivididas, com três repetições. As parcelas receberam os tratamentos de incorporação e as subparcelas, as doses de calcário.

As parcelas foram constituídas por quatro linhas de milho, espaçadas de $0,9 \mathrm{~m}$, com o comprimento de $68,0 \mathrm{~m}$, as quais foram divididas em quatro subparcelas de 17,0 m de comprimento. Foram consideradas como área útil as duas linhas centrais de cada subparcela, desprezando-se $3,5 \mathrm{~m}$ de cada extremidade, compreendendo uma área de $18,0 \mathrm{~m}^{2}$.

A semeadura do milho híbrido $\mathrm{G} 600$ foi realizada em 01 de novembro de 1993, colocando-se seis sementes por metro linear. Efetuou-se adubação básica no sulco de semeadura com $620 \mathrm{~kg} \mathrm{ha}^{-1}$ da fórmula 4-14-8. A adubação nitrogenada de cobertura foi realizada aos 40 dias após a emergência, mediante o emprego de $60 \mathrm{~kg} \mathrm{ha}^{-1} \mathrm{de} \mathrm{N}$, na forma de uréia.

Amostras de solo foram tomadas três meses após a aplicação do calcário, por ocasião da semeadura do milho, utilizando-se trado calador. Foram retiradas doze subamostras de cada subparcela para compor uma amostra composta das profundidades de $0-5 \mathrm{~cm}, 5-10 \mathrm{~cm}, 10-15 \mathrm{~cm}, 15-20$ $\mathrm{cm}, 20-25 \mathrm{~cm}$ e $25-30 \mathrm{~cm}$. Nas amostras de solo coletadas, determinaram-se o $\mathrm{pH}$, os cátions trocáveis e o $\mathrm{H}^{+}+\mathrm{Al}^{3+}$, segundo os métodos descritos por PAVAN et al. (1991).

A avaliação do rendimento de grãos foi realizada mediante colheita manual das espigas e trilhagem em máquina debulhadora estacionária. A 
análise de variância seguiu o modelo em parcelas subdivididas, tendo-se comparado as médias pelo teste de Tukey em nível de 5\% de probabilidade. Mediante análises de regressão por polinômios ortogonais, ajustaram-se equações aos dados de rendimento de grãos e de saturação por bases obtida por profundidade amostrada em função de doses de calcário. Consideraram-se apenas as regressões de maior coeficiente de determinação significativo em nível de $5 \%$.

\section{RESULTADOS E DISCUSSÃO}

A influência de modos de incorporação de calcário sobre o rendimento de grãos do milho é apresentada na figura 1. A precipitação pluvial ocorrida no período compreendido entre a aplicação do calcário e a colheita de milho foi de $1460 \mathrm{~mm}$. O rendimento médio de grãos de milho do experimento foi da ordem de $2.400 \mathrm{~kg} / \mathrm{ha}$. É possível que o rendimento de grãos tenha sido limitado em razão de ter sido utilizada área de campo nativo, recém desbravada, com elevada acidez e teores iniciais de fósforo muito baixos. Nota-se que os maiores aumentos de rendimento de grãos foram observados quando o calcário foi incorporado mediante aplicação de metade da dose antes do arado de discos e a outra após a aração seguida de duas gradagens niveladoras (M1) ou com metade da dose antes da grade aradora e a outra metade após a gradagem seguida de mais

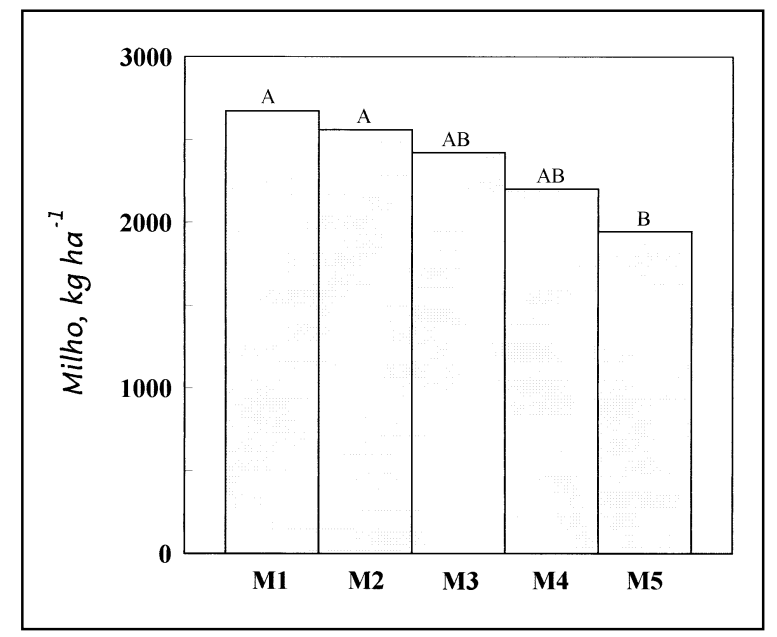

Figura 1 - Efeito de modos de incorporação de calcário sobre o rendimento de grãos de milho cultivado em um Latossolo vermelho-escuro distrófico de campo nativo. Médias seguidas por letras iguais não diferem significativamente pelo teste de Tukey a 5\%. M1 = arado de discos + duas gradagens, M2 = grade aradora + duas gradagens, $\mathrm{M} 3$ = enxada rotativa, $\mathrm{M} 4$ = arado escarificador + duas gradagens e M5 = calcário na superfície sem incorporação. duas gradagens niveladoras (M2). Esses resultados concordam com as recomendações de MUZILLI $\boldsymbol{e} t$ al. (1978) e RAIJ et al. (1985) que sugerem a incorporação do calcário no solo com aplicação de metade da dose antes da aração e a outra metade após a mesma, com posterior gradagem. Neste caso, com base nos resultados obtidos no presente trabalho, a aração poderia ser substituída pela grade aradora.

A calagem aumentou linearmente o rendimento de grãos do milho, de acordo com a dose de calcário aplicada (Figura 2). Respostas positivas da calagem sobre o rendimento de grãos do milho também foram obtidas por GONZALES-ERICO $\boldsymbol{e t}$ al. (1979), CAMARGO et $\boldsymbol{a l}$. (1982) e QUAGGIO $\boldsymbol{e t}$ al. (1985).

Os efeitos de modos de incorporação de calcário sobre a correção da acidez do solo, três meses após a calagem, são mostrados na figura 3. A precipitação pluvial ocorrida durante esse período foi de $656 \mathrm{~mm}$. A calagem proporcionou aumento nos valores de $\mathrm{pH}$ e de saturação por bases, bem como reduziu os teores de alumínio e aumentou os de cálcio e magnésio trocáveis do solo. Tais efeitos foram observados até a camada de $20 \mathrm{~cm}$ quando o calcário foi incorporado com enxada rotativa, até 15 $\mathrm{cm}$ para os modos de incorporação, envolvendo arado de discos ou grade aradora, seguidos de duas gradagens niveladoras e até $10 \mathrm{~cm}$, quando a incorporação foi realizada com arado escarificador mais grade niveladora, ou com a distribuição de calcário na superfície sem incorporação. Esses resultados demonstram que, apesar dos resultados positivos obtidos com a cultura do milho mediante incorporação de calcário na camada de 0-30cm (GONZALES-

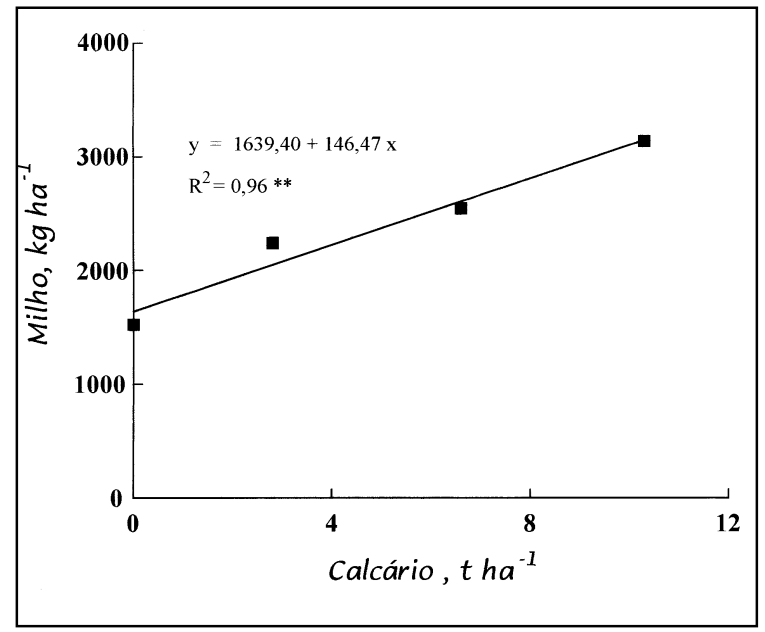

Figura 2 - Efeito de doses de calcário sobre o rendimento de grãos de milho cultivados em um Latossolo vermelho-escuro distrófico de campo nativo. ** Significativo em nível de $1 \%$. 


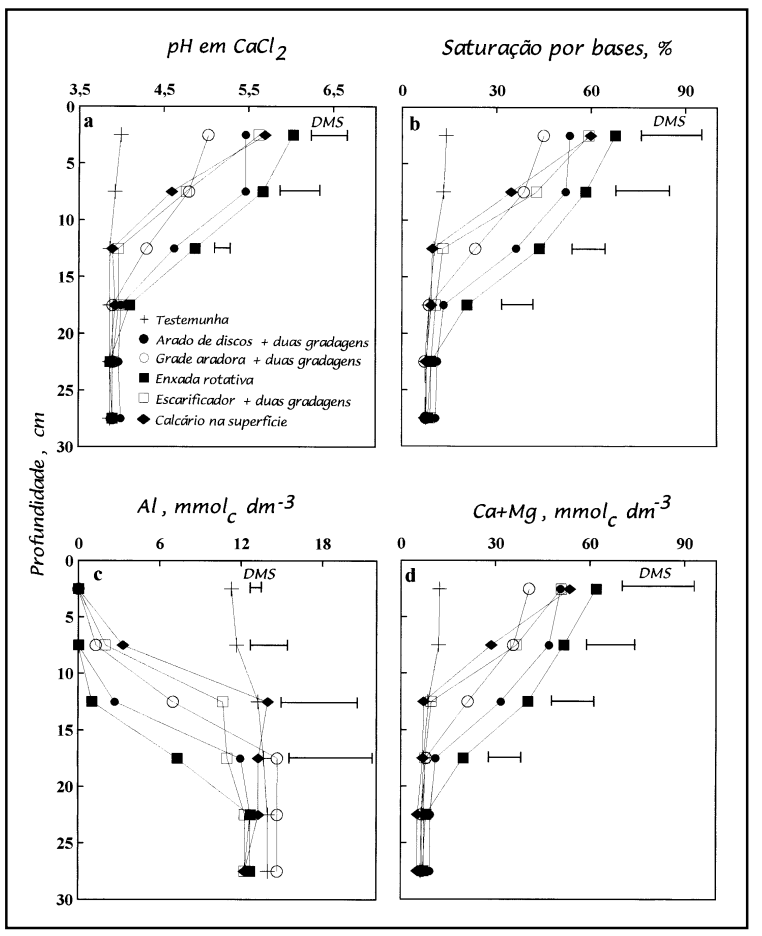

Figura 3 - Valores de $\mathrm{pH}$ em $\mathrm{CaCl}_{2}$ (a) e de saturação por bases (b) e teores de $\mathrm{Al}$ (c) e de $\mathrm{Ca}+\mathrm{Mg}$ (d) trocáveis obtidos com a dose de $10,3 \mathrm{t} \mathrm{ha}^{-1}$ de calcário, em função de modos de incorporação. DMS = teste de Tukey em nível de $5 \%$.

ERICO et al., 1979), deve-se considerar a dificuldade existente para uma incorporação eficiente em camadas mais profundas de solo.

É importante ressaltar que os modos de incorporação que proporcionaram melhor correção da acidez do solo (Figura 3) foram também os que revelaram os maiores rendimentos de grãos (Figura 1). A incorporação de calcário com enxada rotativa, apesar de ter sido eficiente na correção da acidez do solo, deve ter causado problemas às propriedades físicas do solo, tendo em vista que as melhorias das condições de acidez proporcionadas por essa incorporação não refletiram diretamente em aumento de rendimento de grãos. Deve-se considerar ainda como bastante satisfatório o efeito da aplicação de calcário na superfície, sem incorporação, sobre a correção de acidez do solo, tendo em vista o tempo de reação do corretivo de apenas três meses.

Apesar do tempo relativamente curto de reação do calcário no solo, resultados cujos os valores de saturação por bases, determinados após a calagem, foram inferiores aos estimados têm sido comuns na literatura. No trabalho de QUAGGIO $\boldsymbol{e t}$ al. (1982b), a quantidade de calcário, para que fosse atingida a saturação de $70 \%$, foi de aproximada- mente $5 \mathrm{t} \mathrm{ha}^{-1}$, mas uma saturação máxima de $68 \%$ somente foi atingida com aplicação de $12 \mathrm{t} \mathrm{ha}^{-1}$. Resultado semelhante foi obtido por QUAGGIO $\boldsymbol{e t}$ al. (1982a). Devido à diferença observada entre a saturação por bases obtida e a estimada, OLIVEIRA $\boldsymbol{e t}$ al. (1997) sugeriram a recomendação de um índice estimado de $90 \%$ de saturação por bases para calagem na cultura do milho. Um dos motivos levantados para explicar tais efeitos foi a granulometria grosseira do calcário (QUAGGIO et al. 1982a). Esta hipótese, entretanto, não se confirma considerando o trabalho de CAIRES \& ROSOLEM (1993), onde foi utilizado calcário dolomítico "filler" e, mesmo assim, após 120 e 240 dias, os valores de saturação por bases obtidos foram menores que os calculados. Esses autores verificaram que até saturação por bases de 55 a $60 \%$, os resultados obtidos encontravam-se mais próximos aos teóricos, mas, desse ponto em diante, havia grande diferença nos resultados, indicando que o poder tampão do solo era maior que o estimado.

Um outro motivo que poderia ser levantado para explicar esses efeitos seria a incorporação do corretivo de forma não adequada. Em vista disso, foram ajustados modelos às respostas obtidas com a calagem nas diferentes profundidades de amostragem, em função dos modos de incorporação de calcário (Figura 4). Os valores de saturação por bases obtidos, três meses após a calagem, foram inferiores aos estimados, mesmo nas camadas mais superficiais do solo $(0-5 \mathrm{~cm}$ e $5-10 \mathrm{~cm})$, independente do modo de incorporação utilizado. Quando o calcário foi incorporado com enxada rotativa, proporcionando mistura mais íntima do corretivo com o solo, os valores de saturação por bases obtidos nas camadas mais superficiais ficaram mais próximos dos estimados para a camada de 0-20 cm, quando comparado com os demais modos de incorporação. Os resultados deste trabalho indicam que, embora o método de recomendação da necessidade de calagem baseado na elevação da saturação por bases do solo possa aplicar-se bem nas recomendações de rotina, o modo de incorporação do corretivo afeta a sua eficiência. Em condições de campo, mesmo que sejam tomados todos os cuidados necessários com a incorporação do calcário no solo, dificilmente serão alcançados os valores de saturação por bases calculados para a camada arável, três meses após a calagem.

\section{CONCLUSÃO}

O modo de incorporação do corretivo no solo afeta a sua eficiência em relação à profundidade no perfil, na qual há neutralização da acidez, tendo ocorrido elevação da saturação por bases do solo até 


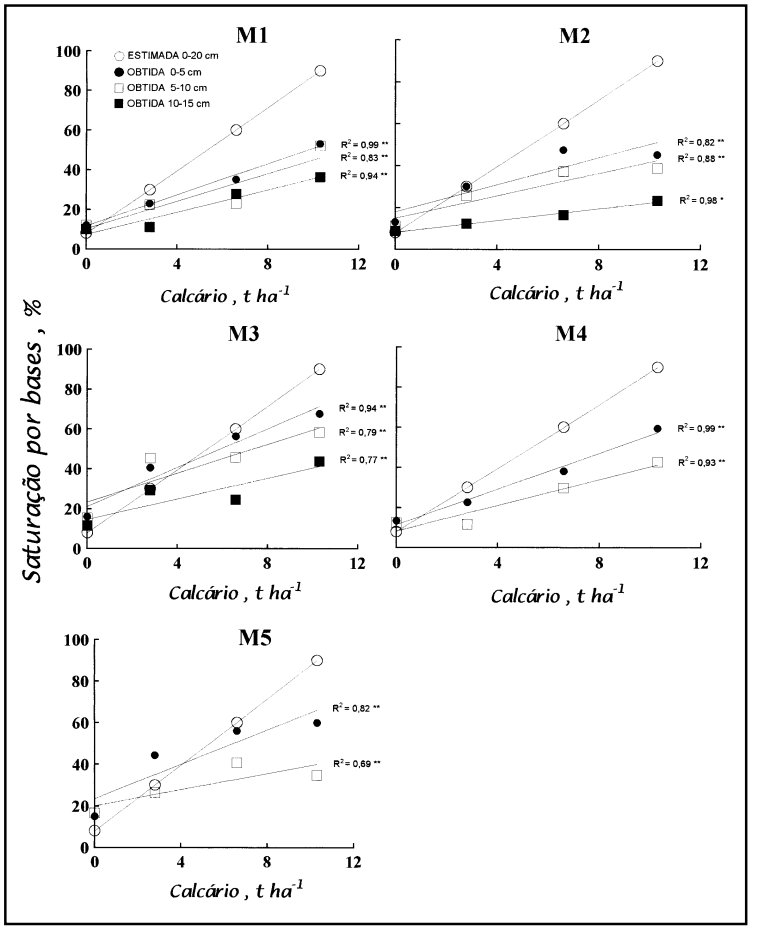

Figura 4 - Saturação por bases estimada e obtida em diferentes profundidades, em função de doses de calcário e modos de incorporação. ** Significativo em nível de $1 \%$ e * Significativo em nível de 5\%. M1 = arado de dis$\cos +$ duas gradagens, M2 = grade aradora + duas gradagens, M3 = enxada rotativa, M4 = arado escarificador + duas gradagens e M5 = calcário na superfície sem incorporação.

a camada de $20 \mathrm{~cm}, 15 \mathrm{~cm}$ e $10 \mathrm{~cm}$, para os seguintes modos de incorporação: enxada rotativa, arado de discos ou grade aradora e arado escarificador ou calcário distribuído na superfície sem incorporação.

\section{REFERÊNCIAS BIBLIOGRÁFICAS}

CAIRES, E.F., ROSOLEM, C.A. Calagem em genótipos de amendoim. R bras Ci Solo, Campinas, v.17, p.193-202, 1993.

CAMARGO, A.P., RAIJ, B. van, CANTARELlA, H., et al. Efeito da calagem nas produções de cinco cultivos de milho, seguidos de algodão e soja. Pesq agropec bras, Brasília, v.17, p.1007-1012, 1982.
EMPRESA BRASILEIRA DE PESQUISA AGROPECUÁRIA (EMBRAPA). Manual de métodos de análise de solo. 2 ed. Rio de Janeiro : Centro Nacional de Pesquisa de Solos, 1997. 212p.

GONZALES-ERICO, E., KAMPRATH, E.J., NADERMAN, G.C., et al. Effect of depth of lime incorporation on growth of corn on an Oxisol of Central Brazil. Soil Sci Soc Am J, v.43, p.1155-1158, 1979.

JACKSON, W.A. Physiological effects of soil acidity. In: PEARSON, R. W., ADAMS, F. (eds). Soil acidity and liming. Madison : American Society of Agronomy, 1967. p.43-124.

MUZILli, O., LANTMANN, A.F., PALHANO, J.B., $\boldsymbol{e} t \boldsymbol{a l}$. Análise de solos: interpretação e recomendação de calagem e adubação para o Estado do Paraná. Londrina : Instituto Agronômico do Paraná, 1978. 49p.

OLIVEIRA, E.L., PARRA, M.S., COSTA, A. Resposta da cultura do milho, em um latossolo vermelho escuro álico, à calagem. R bras Ci Solo, Campinas, v.21, p.65-70, 1997.

OLMOS, J.L.J., CAMARGO, M.N. Ocorrência de toxidez de alumínio nos solos brasileiros, suas características e distribuição. Ci Cult, São Paulo, v.28, p.171-180, 1976.

PAVAN, M.A., BLOCH, M.F., ZEMPULSKI, H.C., et al. Manual de análise química do solo. Londrina : Instituto Agronômico do Paraná, 1991. 33p.

QUAGGIO, J.A., DECHEN, A.R., RAIJ, B. van. Efeitos da aplicação de calcário e gesso sobre a produção de amendoim e lixiviação de bases no solo. R bras Ci Solo, Campinas, v.6, p.189-194, 1982 a.

QUAGGIO, J.A., MASCARENHAS, H.A.A., BATAGLIA, O.C. Resposta da soja à aplicação de doses crescentes de calcário em latossolo roxo distrófico de cerrado. II. Efeito residual. R bras Ci Solo, Campinas, v.6, p.113-118, 1982 b.

QUAGGIO, J.A., RAMOS, V.J., BATAGLIA, O.C., $\boldsymbol{e} \boldsymbol{t} \boldsymbol{a l}$. Calagem para a sucessão batata-triticale-milho usando calcários com diferentes teores de magnésio. Bragantia, Campinas, v.44, p.391-406, 1985.

RAIJ, B. van, Silva, N.M., BATAGLiA, O.C., et al. Recomendações de adubação e calagem para o Estado de São Paulo. Campinas : Instituto Agronômico, 1985. 107p.

RITCHEY, K.D., SOUZA, D.M.G., LOBATO, E., et al. Calcium leaching to increase rooting depth in a savannah Oxisol. Agron J, Madison, v.72, p.40-44, 1980. 